\title{
Greetings to ISRHML Attendees and Researchers
}

\author{
Arthur I. Eidelman
}

\begin{abstract}
$\boldsymbol{B}$ REASTFEEDING MEDICINE welcomes the opportunity to partner with the International Society for Research in Human Milk and Lactation (ISRHML) in publishing the scientific abstracts of the 2016 ISRHML meeting being held in Stellenbosch, South Africa, in March 2016. As ISRHML is a leading scientific organization dedicated to the promotion of research in the field of human milk and lactation, publishing the latest research in Breastfeeding Medicine will facilitate the immediate broad dissemination of the most up-to-date results to the worldwide readers of the Journal. It is our anticipation that upon completion of the various studies being reported herein, that many of the finalized manuscripts will be submitted for consideration for publication in the regular issues of Breastfeeding Medicine. The entire editorial and production staff of Breastfeeding Medicine wishes a rousing success to the ISRHML meeting and for continued mutually productive collaborative work in the future.
\end{abstract}

Arthur I. Eidelman, MD

Editor-in-Chief, Breastfeeding Medicine 